\title{
Polyphasic Taxonomy Leading to the Proposal of Moraxella canis sp. nov. for Moraxella catarrhalis-Like Strains
}

\author{
GEERT JANNES, ${ }^{1}$ MARIO VANEECHOUTTE, ${ }^{2}$ MARTINE LANNOO, ${ }^{3}$ MONIQUE GILLIS, ${ }^{3}$ \\ MARC VANCANNEYT ${ }^{3}$ PETER VANDAMME, ${ }^{3}$ GERDA VERSCHRAEGEN, ${ }^{2}$ \\ HUGO VAN HEUVERSWYN, ${ }^{1}$ AND RUDI ROSSAU ${ }^{1 *}$ \\ Innogenetics N.V., Industriepark Zwijnaarde 7, Box 4, B-9052 Ghent, ${ }^{1}$ and Department of Medical \\ Microbiology, Universitair Ziekenhuis, ${ }^{2}$ and Laboratorium voor \\ Microbiologie, University of Ghent, ${ }^{3}$ B-9000 Ghent, Belgium
}

\begin{abstract}
The taxonomic position of a group of 16 Moraxella catarrhalis-like strains, isolated mainly from dogs, was examined by using morphological tests, biochemical tests, serology, ribotyping with oligonucleotide probes, polymerase chain reaction typing of the $16 S$ rRNA gene and the 16S-23S rRNA gene spacer region, polyacrylamide gel electrophoresis of total proteins, fatty acid profiles, moles percent $G+C$, dot spot and in-solution DNA-DNA hybridizations, and DNA-rRNA hybridizations. It was found that these organisms constitute a distinct cluster within the genus Moraxella. Since they differ genotypically as well as phenotypically from previously described Moraxella species, a new species, Moraxella canis, is proposed to accommodate these isolates. The type strain is LMG 11194 (= N7 = CCUG 8415A).
\end{abstract}

During the testing of the specificity and reliability of DNA probes for the detection of Moraxella catarrhalis, some strains presumptively identified as $M$. catarrhalis on the basis of biochemical and morphological data did not hybridize with some of the probes tested. Additional preliminary genotypic and phenotypic studies indicated that two of these strains were asaccharolytic neisseriae. The other strains, however, resembled $M$. catarrhalis strains but were not identical. This observation prompted us to collect more of these $M$. catarrhalis-like strains and to study this group in more detail.

In this paper we describe the results of a polyphasic taxonomic study in which these strains were compared with other organisms belonging to the recently proposed bacterial family Moraxellaceae (28). This family includes the genera Moraxella, Acinetobacter, and Psychrobacter. It has also been shown that the subgenus Branhamella does not correspond to a genotypic entity and that its four species constitute separate groups in the genus Moraxella. A proposal for the reestablishment of the name $M$. catarrhalis was formulated by Rossau et al. (28).

The results of this study show that the $M$. catarrhalis-like strains, which were isolated mainly from dogs, belong to a new species in the genus Moraxella. The name Moraxella canis is proposed and is used below. Since no genotypic relationship between the genus Moraxella and taxa belonging to the emended family Neisseriaceae has been demonstrated (27), the possibility of a relationship between $M$. canis and genuine Neisseria species could be excluded.

$M$. catarrhalis NCTC 4103 was also included in this study. Since this strain seems to be neither an unequivocal $M$. canis strain nor an unequivocal $M$. catarrhalis strain, no species name is used below when we refer to this strain.

\section{MATERIALS AND METHODS}

Organisms and media used. Data on the origins of the strains included in this study are listed in Table 1. The culture collection strains of $M$. catarrhalis tested were

\footnotetext{
${ }^{*}$ Corresponding author.
}

selected on the basis of different criteria. Strain ATCC 25238 is the type strain. Strains D6, J9, and W3 are lipopolysaccharide (LPS) serotype strains (i.e., strains against which sera were raised and which are serotype strains for serogroups A, B, and C, respectively) (37). Strain U35, which produces $\beta$-lactamase, was kindly provided by $C$. Kamme (17). The following $M$. canis strains, described by the donors as $M$. catarrhalis, were used: CCUG $8415 \mathrm{~A}^{\mathrm{T}}\left(=\mathrm{N} 7^{\mathrm{T}}\right)(\mathrm{T}=$ type strain), supplied by E. Falsen (Culture Collection of the University of Göteborg, Göteborg, Sweden); N4518 (= P37), supplied by J. Y. Riou (Institut Pasteur, Paris, France); and BLU 8387 subclone U33 with large colonies and BLU 8387 subclone U34 with small colonies, supplied by J. Wüst (Zürich University, Zürich, Switzerland). The origin of strain 018 could not be traced. Other $M$. canis strains were isolated by L. A. Devriese (Laboratory of Veterinary Bacteriology, University of Ghent, Ghent, Belgium) after screening of the muzzles of a total of 124 dogs and 36 cats on a selective medium for $M$. catarrhalis (36). Four strains from two dogs (N47 and N48 from one dog and N49 and N50 from the other dog) were withheld for further study since they had a different colony morphology. Type strains and/or representative strains of other Moraxella species were also included. Strains were routinely cultured on Mueller-Hinton agar containing 5\% sheep blood (BBL Microbiology Systems, Cockeysville, Md.) unless indicated otherwise.

Serology. An inhibition enzyme-linked immunosorbent assay (ELISA) with LPS as the specific antigen was performed as described previously (37). Briefly, microtiter plates were coated with LPS type A, B, or C. The ELISA was carried out with homologous antisera previously absorbed with whole-cell suspensions of the strains to be tested. The optical density values measured after inhibition of the LPS-antiserum reactions by the homologous strains were defined as $100 \%$ homology. Inhibition by Moraxella ovis ATCC 19575 was defined as 0\% homology. Percentages of LPS homology for the other strains were calculated from the optical density values measured after inhibition of the LPS-antiserum reactions by these strains by using the following equation: percentage of LPS homology for test strain $=[1-$ (optical density of test strain - optical density of 
TABLE 1. Strains used

\begin{tabular}{|c|c|c|c|c|c|}
\hline \multirow{2}{*}{ Species } & \multicolumn{3}{|c|}{ Culture collection no. ${ }^{a}$} & \multirow{2}{*}{$\begin{array}{c}\text { Country of origin } \\
\text { (year) }\end{array}$} & \multirow{2}{*}{ Source } \\
\hline & UZG & LMG & Others & & \\
\hline M. canis & $N 7^{\mathrm{T}}$ & $11194^{\mathrm{T}}$ & CCUG $8415 \mathrm{~A}^{\mathrm{T}}$ & Sweden (1979) & Dog bite, female \\
\hline M. canis & U33 & 11183 & Wüst BLU 8387 & Switzerland & Blood, male \\
\hline M. canis & U34 & 11184 & Wüst BLU 8387 & Switzerland & Blood, male \\
\hline M. canis & 018 & 11185 & & & \\
\hline M. canis & P37 & 11186 & Riou N4518 & France & Dog sputum \\
\hline M. canis & V44 & 11187 & & Belgium (1991) & Dog muzzle \\
\hline M. canis & V45 & 11188 & & Belgium (1991) & Dog muzzle \\
\hline M. canis & W40 & 11189 & & Belgium (1991) & Dog muzzle \\
\hline M. canis & W4 & 11190 & & Belgium (1991) & Dog muzzle \\
\hline M. canis & W10 & 11191 & & Belgium (1991) & Dog muzzle \\
\hline M. canis & $\mathrm{N} 47$ & & & Belgium (1991) & Dog muzzle \\
\hline M. canis & N48 & & & Belgium (1991) & Dog muzzle \\
\hline M. canis & N49 & & & Belgium (1991) & Dog muzzle \\
\hline M. canis & N50 & & & Belgium (1991) & Dog muzzle \\
\hline M. canis & N51 & & & Belgium (1991) & Dog muzzle \\
\hline M. canis & N53 & & & Belgium (1991) & Cat muzzle \\
\hline M. catarrhalis & & $5128^{\mathrm{T}}$ & CCUG $353^{\mathrm{T}}$, ATCC $25238^{\mathrm{T}}$ & & \\
\hline M. catarrhalis & & $11192^{\mathrm{T}}$ & ATCC $25238^{\mathrm{T}}$ & & \\
\hline M. catarrhalis & B13 & & Nagatake NNBR O43 & Japan & Pneumonia \\
\hline M. catarrhalis & J9 & & Calder A1079 & Scotland (1986) & \\
\hline M. catarrhalis & W3 & & & Belgium (1984) & Sputum \\
\hline M. catarrhalis & D6 & & Calder 55504 & Scotland (1986) & \\
\hline M. catarrhalis & G25 & 11177 & & Belgium (1987) & Sputum \\
\hline M. catarrhalis & J27 & 11178 & & Belgium (1987) & Sputum \\
\hline M. catarrhalis & O29 & 11182 & & Belgium (1988) & Sputum \\
\hline M. catarrhalis & U35 & 11179 & Kamme BC002 Pc ${ }^{\mathrm{R}}$ & Sweden & Nasopharynx, laryngitis \\
\hline M. catarrhalis & V30 & 11180 & & & \\
\hline M. catarrhalis & V31 & 11181 & & & \\
\hline M. catarrhalis & & & ITM 4197 & Belgium & Blood, male \\
\hline $\begin{array}{l}\text { Moraxella sp. } \\
\text { Moraxella sp. }\end{array}$ & X31 & $\begin{array}{l}11193 \\
1133\end{array}$ & $\begin{array}{l}\text { NCTC } 4103 \\
\text { NCTC } 4103\end{array}$ & & \\
\hline M. lacunata & & $5301^{\mathrm{T}}$ & ATCC $17967^{\mathrm{T}}$, CCUG $4441^{\mathrm{T}}$ & & Conjunctivitis \\
\hline M. lacunata & & 1008 & ATCC 17951 & & \\
\hline M. lacunata & & 1009 & ATCC 17952 & & \\
\hline M. lacunata & & 1020 & ATCC 17972 & & Throat, child \\
\hline M. nonliquefaciens & & & ATCC $19975^{\mathrm{T}}$ & & \\
\hline M. nonliquefaciens & & 1010 & ATCC 17953 & & \\
\hline M. nonliquefaciens & & 1011 & ATCC 17954 & & Throat \\
\hline M. bovis & & $5299^{\mathrm{T}}$ & ATCC $10900^{\mathrm{T}}$ & & Cattle, pinkeye \\
\hline M. bovis & & $986^{T}$ & CCUG $2133^{\mathrm{T}}$, ATCC $10900^{\mathrm{T}}$ & & Cattle, pinkeye \\
\hline M. bovis & & 1006 & ATCC 17947 & & Cattle, keratitis \\
\hline M. caviae & & 5129 & & & \\
\hline M. ovis & & $8381^{\mathrm{T}}$ & ATCC $33078^{\mathrm{T}}$ & & Ovine, keratoconjunctivitis \\
\hline M. cuniculi & & $8382^{T}$ & ATCC $14688^{\mathrm{T}}$ & & Rabbit, rhinopharynx \\
\hline M. osloensis & & 6916 & CCUG 63 & Sweden & Urine \\
\hline M. osloensis & & $5131 \mathrm{t}_{1}^{\mathrm{T}}$ & CCUG $350^{\mathrm{T}}$ & & Cerebrospinal fluid \\
\hline M. osloensis & & 1043 & ATCC 19961 & & Urine \\
\hline P. immobilis & & $6784 t_{1}$ & CCUG 9702 & & Lemon sole, gills \\
\hline A. calcoaceticus & & $1046^{T}$ & $\operatorname{ATCC} 23055 t_{1}{ }^{T}$ & & Soil \\
\hline N. gonorrhoeae & & & NCTC $8375^{\mathrm{T}}$ & & \\
\hline$N$. canis & & & $\operatorname{ATCC} 14687^{\mathrm{T}}$ & & \\
\hline
\end{tabular}

${ }^{a}$ Abbreviations: ATCC, American Type Culture Collection, Rockville, Md.; CCUG, Culture Collection, Department of Clinical Bacteriology, University of Göteborg, Göteborg, Sweden; ITM, Institute for Tropical Medicine, Antwerp, Belgium; LMG, Culture Collection, Laboratorium voor Microbiologie, Universiteit Gent, Ghent, Belgium; NCTC, National Collection of Type Cultures, Central Public Health Laboratory, London, England; UZG, Universitair Ziekenhuis, Ghent, Belgium. 


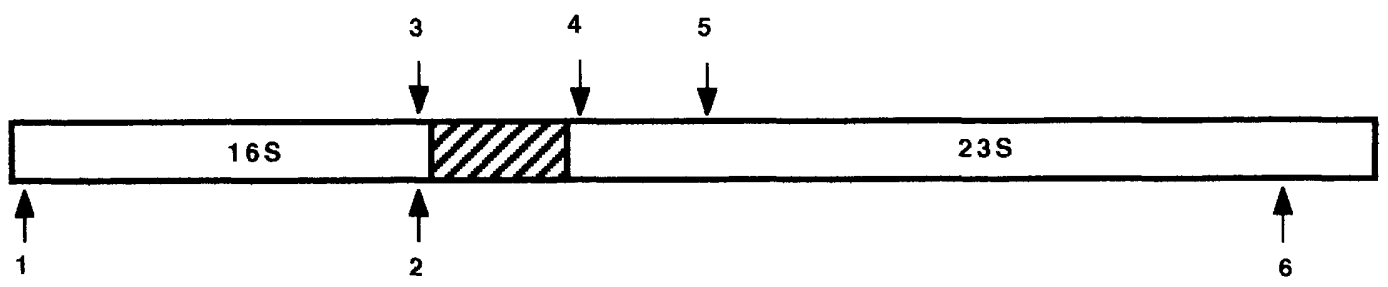

\section{1: TGGCTCAGATTGAACGCTGGCGGC \\ 2: TACCTTGTTACGACTTCACCCCA \\ 3 : TGGGGTGAAGTCGTAACAAGGTA \\ 4: CACGTCCTTCGTCGCCT \\ 5: ACCAGTACCGTGAGGGAAAGG \\ 6 : GGACCGAACTGTCTCACGACGTTCT}

FIG. 1. Sequences and locations of the oligonucleotides used as probes and/or primers. The sequences of these primers and probes are quasiconserved in eubacteria. The cross-hatched area represents the spacer region between the $16 \mathrm{~S}$ and $23 \mathrm{~S}$ rRNA genes.

homologous strain)/(optical density of $M$. ovis strain optical density of homologous strain)] $\times 100$.

Levels of total antigenic homology were determined as follows. ELISA microtiter plates were coated with tryptic soy broth culture supernatants (called whole-cell antigen preparations) of each strain to be tested. The ELISA was carried out as described by Voller et al. (39) with anti-J9 serum. The optical density value measured for the coated whole-cell preparation of $M$. catarrhalis $\mathrm{J} 9$ was defined as $100 \%$ homology. The levels of total antigeneic homology for the other strains were calculated as follows: percentage of total antigenic homology for test strain $=$ (optical density of test strain/optical density of strain ATCC $\left.25238^{\mathrm{T}}\right) \times 100$.

Biochemical characteristics. Butyrate esterase activity was tested by using 4-methylumbelliferyl butyrate as the substrate (35). $\gamma$-Glutamyl-aminopeptidase disks (Rosco Diagnostics, Taastrup, Denmark) were used to test for the presence of this enzyme. The presence of extracellular DNase was determined on DNase agar (Oxoid, Ltd., London, United Kingdom). Growth on a medium containing acetazolamide was used to evaluate the absence of carbonic anhydrase (36). All other tests were performed as described by McFaddin (23).

Oligonucleotide synthesis, purification, and labelling. The oligonucleotides used as primers or probes were synthesized by the phosphite-triester method with a Cyclone 8400 DNA synthesizer (New Brunswick Scientific, Edison, N.J.). The oligonucleotides were deprotected and precipitated by using a double volume of ethanol. The oligonucleotides used as hybridization probes were $5^{\prime}$ labelled by using $\left[\gamma^{32} \mathrm{P}\right] \mathrm{ATP}$ and T4 polynucleotide kinase (Pharmacia, Uppsala, Sweden) (20). The sequences and locations of the oligonucleotides used as probes or primers are shown in Fig. 1.

PCR analysis. Purified whole-cell DNA (approximately $100 \mathrm{ng}$ per reaction) was amplified by using the polymerase chain reaction (PCR) technique with conserved primers 1 and 2 and conserved primers 3 and 4 , resulting in the amplification of the 16S rRNA gene and the 16S-23S rRNA gene spacer region, respectively (Fig. 1). The $\mathrm{PCR}$ reactions were performed in $50 \mu \mathrm{l}$ of a solution containing $200 \mu \mathrm{M}$ dATP, $200 \mu \mathrm{M}$ dCTP, $200 \mu \mathrm{M}$ dGTP, $200 \mu \mathrm{M}$ dTTP (all four deoxynucleoside triphosphates were obtained from Boehringer Mannheim, Mannheim, Germany), $50 \mathrm{pmol}$ of each of the primers, $1 \times$ PCR buffer (Stratagene Cloning Systems, La Jolla, Calif.), and $2 \mathrm{U}$ of Taq polymerase (Stratagene). Initial denaturation at $95^{\circ} \mathrm{C}$ for $5 \mathrm{~min}$ was followed by 30 cycles consisting of annealing at $50^{\circ} \mathrm{C}$ for $1 \mathrm{~min}$, extension at $72^{\circ} \mathrm{C}$ for $1 \mathrm{~min}$, and denaturation at $95^{\circ} \mathrm{C}$ for $1 \mathrm{~min}$. Finally, additional extension occurred at $72^{\circ} \mathrm{C}$ for $7 \mathrm{~min}$, after which the samples were cooled to room temperature and extracted with $\mathrm{CHCl}_{3}$. The amplified products from the reactions with primers 1 and 2 and the reactions with primers 3 and 4 were electrophoresed in 1.6 and $1.8 \%$ (wt/vol) agarose gels, respectively, at $8 \mathrm{~V} / \mathrm{cm}$ for $90 \mathrm{~min}$. Restriction endonucleases were purchased from Boehringer Mannheim or New England Biolabs, Beverly, Mass., and were used according to the manufacturers' recommendations.

Standard molecular genetic techniques. High-molecularweight whole-cell DNA was purified essentially as described by Marmur (22). Nick translation was performed as described by Maniatis et al. (20). A $1-\mu \mathrm{g}$ portion of purified whole-cell DNA was digested to completion with HindIII restriction endonuclease (Boehringer Mannheim), loaded onto a $1 \%(\mathrm{wt} / \mathrm{vol})$ agarose gel, and electrophoresed at 8 $\mathrm{V} / \mathrm{cm}$ for $90 \mathrm{~min}$. The DNA fragments were transferred to Zeta-Probe nylon membranes (Bio-Rad Laboratories, Richmond, Calif.) under alkaline conditions (24). Genomic DNA (1 $\mu \mathrm{g}$ per spot) was dot spotted as described previously (29). The membranes were hybridized as described below. Prehybridizations were performed in a solution containing $3 \times$ SSC $(1 \times$ SSC is $0.15 \mathrm{M} \mathrm{NaCl}$ plus $0.015 \mathrm{M}$ sodium citrate [pH 7.0]), $20 \%$ (vol/vol) deionized formamide, $25 \mathrm{mM}$ sodium phosphate buffer ( $\mathrm{pH} 7.1$ ), $1 \%$ (wt/vol) sodium dodecyl sulfate (SDS), $0.02 \%$ (wt/vol) Ficoll, $0.02 \%$ (wt/vol) bovine serum albumin, $0.02 \%$ (wt/vol) polyvinylpyrrolidone, and $0.1 \mathrm{mg}$ of sheared, denatured salmon sperm DNA per ml for 0.5 to $1 \mathrm{~h}$ at $45^{\circ} \mathrm{C}$. Hybridizations were performed at the same temperature for $4 \mathrm{~h}$ to overnight in a mixture that was the same as the prehybridization mixture except that approximately $10^{6} \mathrm{cpm}$ of ${ }^{32} \mathrm{P}$-labeled oligonucleotide probe or nick-translated genomic DNA per $\mathrm{ml}$ was added. After a brief rinse at room temperature in wash solution $(3 \times \mathrm{SSC}$, $20 \%$ formamide, $25 \mathrm{mM}$ sodium phosphate buffer [pH 7.1]) containing $0.1 \%$ SDS, the membranes were finally washed for $30 \mathrm{~min}$ at the hybridization temperature in wash solution containing $1 \%$ SDS. The membranes were then rinsed at room temperature in $1.5 \times \mathrm{SSC}-0.1 \% \mathrm{SDS}$ for about $10 \mathrm{~min}$ and autoradiographed by using Fuji RX film (Fuji Photo Film, Tokyo, Japan) at $-70^{\circ} \mathrm{C}$ and an intensifying screen.

PAGE of whole-cell proteins. All strains were grown for 48 $\mathrm{h}$ on heart infusion medium (Difco Laboratories, Detroit, Mich.) at $28^{\circ} \mathrm{C}$ in Roux flasks. Whole-cell protein extracts were prepared, and SDS-polyacrylamide gel electrophoresis 
(PAGE) was performed by using the procedure of Laemmli (18), slightly modified as described previously (34).

Numerical analysis of the protein gel electropherograms. Densitometric analysis, normalization, and interpolation of the protein profiles and numerical analysis were performed by using the GelCompar 1.3 software package (Helix C.V., Biotechnology Business Development, Ghent, Belgium). The profiles were recorded and stored on a PC-AT computer. The similarity between pairs of traces was expressed by the Pearson product moment correlation coefficient (31), converted for convenience to a percentage.

DNA base composition. Melting curves were determined by the thermal denaturation method (11), and the average $\mathrm{G}+\mathrm{C}$ contents were calculated by using the equation of Marmur and Doty (21), as modified by De Ley (8).

DNA-DNA hybridizations. The degree of binding, expressed as a percentage, was determined spectrophotometrically by using the initial renaturation method (9). Renaturations were performed in $1 \times \mathrm{SSC}$ at the optimal renaturation temperature $\left(64.9^{\circ} \mathrm{C}\right)$ with a total DNA base pair concentration of $0.92 \mathrm{mM}$. Degrees of binding of $25 \%$ and less were not significant.

DNA-rRNA hybridizations. DNA was further purified by $\mathrm{CsCl}$ gradient centrifugation, thermally denatured, and fixed on cellulose nitrate filters (type SM11358; Sartorius, Göttingen, Germany), as described previously (10). ${ }^{3} \mathrm{H}$-labeled $23 \mathrm{~S}$ rRNA from Moraxella lacunata subsp. liquefaciens ATCC 17952 was prepared as described by Rossau et al. (28). Hybridizations and determinations of $T_{m(e)}$ (the temperature at which one-half of a DNA-rRNA duplex was denatured) were performed as described elsewhere (28).

Gas chromatographic analysis of cellular fatty acid methyl esters. Bacterial strains were precultured on heart infusion agar slants, streaked onto plates containing 3.0\% (wt/vol) Trypticase soy broth (BBL) supplemented with $1.5 \%$ (wt/ vol) Bacto Agar (Difco), and incubated at $28^{\circ} \mathrm{C}$ for $24 \mathrm{~h}$. Approximately $60 \mathrm{mg}$ (wet weight) of cells was harvested from the most dilute quadrant showing confluent growth. The extraction of fatty acids, preparation of methyl esters and separation of methyl esters by gas-liquid chromatography were performed as described previously (38). Fatty acid methyl ester fingerprints were identified by using the Microbial Identification System software package (version 3.2; Microbial ID, Inc., Newark, Del.).

\section{RESULTS AND DISCUSSION}

A random selection of 60 strains of $M$. catarrhalis out of a collection of about 1,000 strains (Universitair Ziekenhuis, Ghent, Belgium) from different clinical and geographical origins included 2 strains which were oxidase- and catalasepositive, gram-negative diplococci and exhibited butyrate esterase and extracellular DNase activities. However, colony morphology on Mueller-Hinton agar containing 5\% sheep blood more closely resembled that of members of the Enterobacteriaceae (large, smooth colonies) than that of typical $M$. catarrhalis strains (gliding, butyrous colored colonies). Consequently, these strains $\left(N 7^{T}\right.$, isolated from a dog bite, and O18, of unknown origin) were considered atypical $M$. catarrhalis strains. Subsequent genetic investigations showed that these strains did not hybridize to some of the rRNA-derived DNA probes designed for specific detection of $M$. catarrhalis strains, indicating that these strains may belong to a different, possibly undescribed, taxon.

In the meantime, three other $M$. catarrhalis isolates (U33,
U34, and P37) described in the literature were supplied by different investigators. Strain P37 was isolated from dog sputum and was described as "atypical" (26). U33 and U34 were subclones from the same strain isolated from the blood of a 61-year-old male human in Switzerland (40). The aberrant characteristics of strains U33 and U34 were noted by the authors, but Wüst et al. presumptively assigned these strains to $M$. catarrhalis on the basis of chemotaxonomic data. Since strains U33 and U34 had been found to be $\gamma$-glutamyl-aminopeptidase positive (40), the other atypical strains were tested for this characteristic and found to be equally positive, in contrast to typical $M$. catarrhalis strains. Also, another aberrant $M$. catarrhalis strain (NCTC 4103) described in the literature $(3,7)$ was found to produce $\gamma$-glutamyl-aminopeptidase. This extra biochemical characteristic enabled us to search for more similar isolates.

Since it was striking that one strain (P37) came from dog sputum and that another strain $\left(N 7^{\mathrm{T}}\right)$ was associated with a dog bite wound, we used a medium selective for $M$. catarrhalis (36) to culture swabs taken from the mouths of dogs and cats attending a university hospital day care clinic for pets. Different colony types were picked, Gram stained and tested for oxidase, butyrate esterase, extracellular DNase, and $\gamma$-glutamyl aminopeptidase activities. From the cultured salivas of 124 dogs and 36 cats, a total of 11 strains were found to be gram-negative cocci which were positive for the four biochemical tests. All strains which were isolated from animals were recovered in low numbers ( $<50$ CFU per selective plate). Their presence would probably have been overlooked if nonselective media had been used. No pathogenic role could be ascertained. All 11 isolates from dogs and cats, together with strains $\mathrm{N}^{\mathrm{T}}$, O18, P37, U33, and U34, were examined in more detail and compared with typical $M$. catarrhalis strains, strain NCTC 4103, and strains belonging to other Moraxella species by using a variety of techniques, as described below.

Colony morphology. $M$. catarrhalis strains produce typical colonies when they are grown on solid media; the butyrous colored colonies can be shifted around (hockey puck test) and can be picked from the agar without losing their semiconvex shape. Strain NCTC 4103 produces small, greyish colonies which more closely resemble those of nonhemolytic Neisseria spp. The colonies of strain W40 resemble colonies of $M$. catarrhalis, while other $M$. canis strains produce large, smooth colonies that look more like colonies of members of the Enterobacteriaceae. Some strains (N49, $\mathrm{P} 37, \mathrm{U} 33$, and U34) produce very slimy colonies resembling colonies of Klebsiella pneumoniae.

The production of a brown pigment when the organisms are grown on starch-containing Mueller-Hinton agar is also typical of most $M$. canis strains (except U34). Strain NCTC 4103 produces a faint brown pigment, while the $M$. catarrhalis, "false Neisseria"' spp., and the Moraxella strains tested never showed pigmentation. Furthermore, most $M$. catarrhalis strains and strain NCTC 4103 show strong autoagglutination when colonies are suspended in a physiological solution. This autoagglutination is weakened but persists after boiling for $5 \mathrm{~min}$. Autoagglutination, which disappeared after boiling, was observed for only three $M$. canis strains (N48, N53, and W4).

Biochemical characteristics. Biochemical characteristics were determined for all of the $M$. canis strains examined. The following characteristics are common to $M$. catarrhalis, $M$. canis, strain NCTC 4103, and most Moraxella species: strains are positive for oxidase and catalase activities; carbonic anhydrase is not present; no acid is produced from 
TABLE 2. Differentiating phenotypic characteristics of Moraxella species $^{a}$

\begin{tabular}{|c|c|c|c|c|c|c|c|c|c|c|c|}
\hline \multirow{2}{*}{ Taxon } & \multicolumn{2}{|c|}{ Cell shape } & \multirow{2}{*}{$\begin{array}{l}\gamma \text {-Glutamyl- } \\
\text { aminopeptidase } \\
\text { activity }\end{array}$} & \multirow{2}{*}{$\begin{array}{l}\text { DNase } \\
\text { activity }\end{array}$} & \multirow{2}{*}{$\begin{array}{c}\text { Growth on } \\
\text { medium } \\
\text { containing mineral } \\
\text { salts and } \\
\text { ammonium } \\
\text { acetate }\end{array}$} & \multirow{2}{*}{$\begin{array}{l}\text { Growth } \\
\text { stimulated } \\
\text { by bile } \\
\text { salts }\end{array}$} & \multirow{2}{*}{$\begin{array}{c}\text { Growth } \\
\text { inhibited } \\
\text { by bile } \\
\text { salts }\end{array}$} & \multirow{2}{*}{$\begin{array}{l}\text { Growth on } \\
\text { Mueller- } \\
\text { Hinton agar } \\
\text { at room } \\
\text { temp }\end{array}$} & \multirow{2}{*}{$\begin{array}{l}\text { Nitrate } \\
\text { reduction }\end{array}$} & \multirow{2}{*}{$\begin{array}{l}\text { Nitrite } \\
\text { reduction }\end{array}$} & \multirow{2}{*}{$\begin{array}{c}\text { Brown pigment } \\
\text { on Mueller- } \\
\text { Hinton agar }\end{array}$} \\
\hline & Rods & Cocci & & & & & & & & & \\
\hline M. lacunata & $t^{b}$ & - & - & - & - & - & + & - & + & - & - \\
\hline M. bovis & + & - & - & - & - & - & + & - & $(-)$ & - & - \\
\hline M. nonliquefaciens & + & - & - & - & - & - & + & - & + & - & - \\
\hline M. atlantae & + & - & NT & - & - & + & NT & NT & - & - & - \\
\hline M. phenylpyruvica & + & - & $(-)$ & - & $(-)$ & + & NT & NT & $(+)$ & - & - \\
\hline M. osloensis & + & - & $(-)$ & - & $(+)$ & - & d & + & $\mathrm{d}$ & - & - \\
\hline M. canis & - & + & + & + & $(+)$ & - & $(-)$ & + & $(+)$ & d & $(+)$ \\
\hline $\begin{array}{l}\text { Moraxella sp. strain } \\
\text { NCTC } 4103\end{array}$ & - & + & + & + & - & - & + & + & - & + & w \\
\hline M. catarrhalis & - & + & - & + & - & - & + & - & $(+)$ & $(+)$ & - \\
\hline M. caviae & - & + & - & + & - & - & + & - & + & $(+)$ & - \\
\hline M. ovis & - & + & - & + & - & - & + & - & $(+)$ & - & - \\
\hline M. cuniculi & - & + & - & + & - & - & + & - & - & - & - \\
\hline
\end{tabular}

${ }^{a}$ Data from this study and reference 5.

$b_{+}$, all strains positive; $(+)$, most strains positive; d, results differ among strains; - , all strains negative; $(-)$, most strains negative; w, weak reaction; NT, not tested.

glucose, maltose, saccharose, or lactose; strains do not hemolyze human blood (except Moraxella bovis, Moraxella caviae, and $M$. ovis) or sheep blood (except $M$. bovis and $M$. ovis); gelatin is not liquefied; serum is not liquefied (except $M$. bovis and $M$. lacunata); no growth occurs at $5^{\circ} \mathrm{C}$ or in the presence of $6 \% \mathrm{NaCl}$; growth is not stimulated by bile salts; no phenylalanine deaminase or urease activity is present; no indole is produced; strains are susceptible to $1.0 \mathrm{U}$ of penicillin per $\mathrm{ml}$ (except $\beta$-lactamase-producing strains, which are found in most species [M. canis W4 is $\beta$-lactamase positive]); no polysaccharides are synthesized from saccharose; butyrate esterase activity is present; no lipase or lecithinase activity can be detected; and strains are unable to hydrolyze starch.

The most prominent phenotypic features differentiating $M$. canis strains from strains of other Moraxella species are summarized in Table 2 . Since $M$. canis is the only Moraxella species besides $M$. catarrhalis and the "false neisseriae" which produces extracellular DNase, $M$. canis may be presumptively misidentified as one of these taxa by using conventional criteria. However, $M$. canis strains can be clearly distinguished from $M$. catarrhalis, $M$. ovis, $M$. cuniculi, and $M$. caviae. In general, $M$. canis strains are less fastidious than strains of other authentic Moraxella species, and in this respect they resemble Moraxella osloensis strains more closely. Like $M$. osloensis strains and in contrast to other authentic moraxellae, all $M$. canis strains grow on Mueller-Hinton agar at room temperature, and most strains are able to grow on medium containing mineral salts and ammonium acetate (except U34 and N47), lactose bromothymol blue agar (except U34), eosine-methylene blue agar (except U34), and MacConkey agar (except U34). Furthermore, the growth of $M$. canis strains except U33 and U34 is not inhibited by bile salts. Unlike $M$. catarrhalis strains, $M$. canis strains exhibit a rather slow butyrate esterase reaction (15 min, compared with $5 \mathrm{~min}$ ), when they are tested with 4-methylumbelliferyl butyrate as the substrate.

However, typical for $M$. canis strains is the production of $\gamma$-glutamyl-aminopeptidase, which is considered to be absent in most Moraxella species (6), although Riou et al. (25) found $\gamma$-glutamyl-aminopeptidase activity in two Moraxella phenylpyruvica strains examined and the presence of this enzyme could also be demonstrated in one of six $M$. osloensis strains examined in our laboratories (strain ATCC 19961). These criteria, together with colony morphology, can be used for differentiation of $M$. canis from $M$. catarrhalis and other authentic Moraxella species. Cell shape and DNase production allow differentiation of $M$. canis from $M$. osloensis strains. Phenotypic features that differentiate $M$. canis from Neisseria species, including Neisseria canis and asaccharolytic true neisseriae, are the presence of butyrate esterase and DNase activities and the absence of carbonic anhydrase activity.

Habitat. The habitats of $M$. canis and $M$. catarrhalis seem to be well separated. Normally, $M$. catarrhalis occurs in the upper respiratory tracts of humans, while most $M$. canis strains were found in the upper respiratory tracts of dogs and cats. Strains $N 7^{\mathrm{T}}, \mathrm{U} 33$, and U34, which were isolated from humans, were obtained from unusual sources; association with the muzzle of a dog is clear in the case of strain $N 7^{\mathrm{T}}$, which was isolated from a dog bite wound. During this and previous studies we could not isolate genuine $M$. catarrhalis strains from the upper respiratory tracts of dogs or cats, nor could we isolate $M$. canis from human upper respiratory tracts. Yet, the isolation of $M$. catarrhalis from dogs was previously reported by Saphir and Carter (30) and Bailie et al. (2). However, it should be noted that these authors probably used conventional identification criteria by which $M$. catarrhalis strains and $M$. canis strains cannot easily be differentiated. Bailie et al. (2) also described the isolation of $M$. osloensis from dogs, although the normal habitat of $M$. osloensis is probably the human upper respiratory tract.

Serology. (i) LPS. On the basis of their LPS antigenicities, $M$. catarrhalis strains can be subdivided into three types (types A, B, and C); about $7 \%$ of the strains are nontypeable (37). When this typing system was used, it was found that the LPS type of $M$. canis strains is closely related to the most common $M$. catarrhalis LPS type (type A). Strains $\mathbf{N 7}^{\mathbf{T}}$, O18, P37, V44, V45, W40, and NCTC 4103 gave between 60 and $80 \%$ inhibition in an inhibition ELISA specific for LPS type A. Although the levels of inhibition with strains U33 and U34 were less than $30 \%$ with respect to $M$. catarrhalis 
LPS type A, B, or C and these strains seem to possess the least closely related LPS among the $M$. canis strains tested, Wüst et al. (40) showed that the LPS of these strains still exhibited sufficient antigenic similarity to immunoprecipitate anti- $M$. catarrhalis serum. $M$. catarrhalis type B and C strains gave less than $50 \%$ inhibition, and hence, their LPS are serologically more distant from the LPS of type A strains than the LPS of $M$. canis strains are. The levels of inhibition observed with the other members of the Moraxellaceae tested (11 strains belonging to the following six species: $M$. lacunata, $M$. osloensis, $M$. nonliquefaciens, $M$. ovis, $M$. caviae, and $M$. cuniculi) and $N$. canis did not exceed $20 \%$ for all three $M$. catarrhalis LPS types.

(ii) Total antigeneic homology. The optical density measured after an ELISA carried out with a whole-cell preparation of $M$. catarrhalis type strain ATCC 25238 as the coating antigen was defined as $100 \%$. The optical densities for the 11 other $M$. catarrhalis strains and for strain NCTC 4103 were more than $85 \%$. The optical densities for $M$. canis strains ranged between 20 and $70 \%$, and the optical densities were $60 \%$ for $M$. ovis, $35 \%$ for $M$. cuniculi, and 35 and $25 \%$ for $M$. caviae. The optical densities for other Moraxella species and for $M$. canis U34 were less than $20 \%$ of the optical density obtained when the $M$. catarrhalis ATCC $25238^{\mathrm{T}}$ broth culture supernatant was the coating antigen.

(iii) Serological cross-reactivity with Neisseria meningitidis serum. Wüst et al. (40) also reported that strains U33 and U34 cross-agglutinate with $N$. meningitidis ACYW135 antiserum. We found that this characteristic was present in 12 of the $16 \mathrm{M}$. canis strains tested. Because of autoagglutination of $M$. catarrhalis strains and strain NCTC 4103, agglutination with $N$. meningitidis antiserum was not interpretable.

From these data it can be concluded that $M$. canis strains are serologically more closely related to $M$. catarrhalis than to most other Moraxella species, including the "false neisseriae." Moraxella spp. possess the rough type of LPS, and thus, when the low number of possible epitopes on these small molecules is taken into account, serological crossreactions could be expected to occur between closely related species. However, total antigeneic homology, as determined by an ELISA, enables differentiation between $M$. catarrhalis and $M$. canis. Strain NCTC 4103 is serologically indistinguishable from $M$. catarrhalis strains.

Comparative protein gel electrophoresis (SDS-PAGE). Figure 2 shows a dendrogram based on an average-linkage cluster analysis of SDS-PAGE protein patterns from $M$. canis strains and representative strains of $M$. catarrhalis and other Moraxella species. Figure 3 shows the corresponding electropherograms of the $M$. canis and $M$. catarrhalis strains and the two subcultures (LMG 1133 and LMG 11193) of Moraxella sp. strain NCTC 4103. All of the $M$. catarrhalis strains studied belong to a separate cluster, and $M$. ovis type strain LMG 8381 is the closest neighbor of this cluster (Fig. 2). Eight strains of $M$. canis constitute another electrophoretic cluster. U33 and U34 cluster separately. However, a visual comparison of the protein profiles of the latter two strains reveals several similarities with the protein profiles of $M$. canis strains belonging to cluster I (Fig. 3). The heavy protein band in the 34,000 -molecular-weight region is at the origin of a separate position on the dendrogram. Deletion of this dense protein band from the numerical analysis resulted in the grouping of all $M$. canis strains in a single cluster (data not shown). All other Moraxella species occupy gel electrophoretic positions outside clusters I, II, and IV. Subcultures LMG 1133 and LMG 11193 of Moraxella sp. strain NCTC 4103 also constitute a separate gel electrophoretic cluster (cluster III), confirming the intermediate position of these taxa. The two subcultures produced very similar electropherograms (Fig. 3).

Fatty acid analysis. The fatty acid profiles of strains of seven Moraxella species (M. bovis, $M$. canis, $M$. catarrhalis, $M$. lacunata, $M$. nonliquefaciens, $M$. osloensis, and $M$. ovis) and of strain LMG 1133 are shown in Table 3. The major fatty acids of the strains studied are $\mathrm{C}_{10: 0}, \mathrm{C}_{12: 0} 3-\mathrm{OH}$, $C_{16: 1}$ cis-9, $C_{16: 0}, C_{18: 3}$ cis-6,12,14, and $C_{18: 1}$ cis-9. Our results largely corroborate previously reported results (13, $15,16,19,40)$. Mostly quantitative differences in fatty acid composition were observed; these differences may have been due to the cultivation conditions used.

In our study, oleic acid $\left(\mathrm{C}_{18: 1}\right.$ cis-9) was detected as one of the major fatty acid components of all species studied. Sugimoto et al. (33) divided Moraxella species into two groups, the oleic acid group and the cis-vaccenic acid $\left(\mathrm{C}_{18: 1}\right.$ cis-11) group. The latter group is characterized by the absence of oleic acid and includes the type strains of $M$. catarrhalis and $M$. ovis. When the Microbial Identification System was used, only $M$. canis and $M$. catarrhalis showed trace amounts of summed feature 7 (which includes cisvaccenic acid [Table 3]). Like all of the strains studied, $M$. catarrhalis and $M$. ovis were characterized by high amounts of oleic acid. It is not clear whether different cultivation conditions are responsible for these discrepancies. As shown in Table 3, M. canis strains contain the highest mean percentage of $\mathrm{C}_{18: 1}$ cis $-9(67.8 \%)$ and the lowest amounts of $\mathrm{C}_{16: 0}(1.2 \%)$ and $\mathrm{C}_{16: 1}$ cis $-9(8.8 \%)$. Strains of this species can be further differentiated from $M$. catarrhalis strains by the presence of small amounts of $C_{17: 0}$ iso. The fatty acid pattern of strain LMG 1133 is similar to the profile of $M$. catarrhalis strains. Minor quantitative differences and the presence of small amounts of $C_{16: 0}$ iso and $C_{17: 0}$ iso and the absence of $\mathrm{C}_{17: 1} \mathrm{~B}$ differentiate strain LMG 1133 from $M$. catarrhalis strains. Also, the profiles of $M$. osloensis strains are quantitatively very similar to the profiles of $M$. catarrhalis strains, but can be distinguished by the absence of $\mathrm{C}_{12: 0}$ and $\mathrm{C}_{14: 0} . M$. ovis has the highest percentage of summed feature $3(6.6 \%)$. The fatty acid profiles of the type strain of $M$. bovis and two strains of $M$. lacunata are very similar; compared with other species, considerable quantitative differences in the major fatty acids are observed. These two species can be differentiated by the presence or absence of some minor fatty acids. $M$. nonliquefaciens had the lowest amount of $\mathrm{C}_{18: 1}$ cis-9 $(20.7 \%)$ and the highest amounts of $\mathrm{C}_{12: 0}(8.3 \%)$, $\mathrm{C}_{12: 0} 3-\mathrm{OH}(14.4 \%)$, ECL 15549 (5.5\%), $\mathrm{C}_{16: 0}(12.4 \%)$, and $\mathrm{C}_{18: 3}$ cis-6,12,14 (7.4\%). The fatty acid profile of the $M$. canis strains differs significantly from that of the Centers for Disease Control group NO-I strains, which are fastidious, nonoxidative, gram-negative organisms associated with dog and cat bites (14).

rRNA gene restriction patterns. Ribotyping (12) has proven to be an interesting tool for taxonomic purposes. In this study, we used a slightly modified technique, as outlined below. Genomic DNAs of different bacterial strains were cleaved to completion with HindIII, electrophoresed in agarose gels, and transferred to membranes. The fragments carrying rRNA gene sequences were localized by hybridization with oligonucleotide probes hybridizing to conserved regions on the $16 \mathrm{~S}$ or $23 \mathrm{~S}$ rRNA gene instead of with an Escherichia coli $16 \mathrm{~S}+23 \mathrm{~S}$ rRNA probe, which is what was used in most of the previous studies dealing with ribotyping. In this study a mixture of three oligonucleotide probes (probes 1, 5, and 6) was used. The locations of these probes on the $16 \mathrm{~S}$ and $23 \mathrm{~S}$ rRNA gene are shown in Fig. 1. Figure 


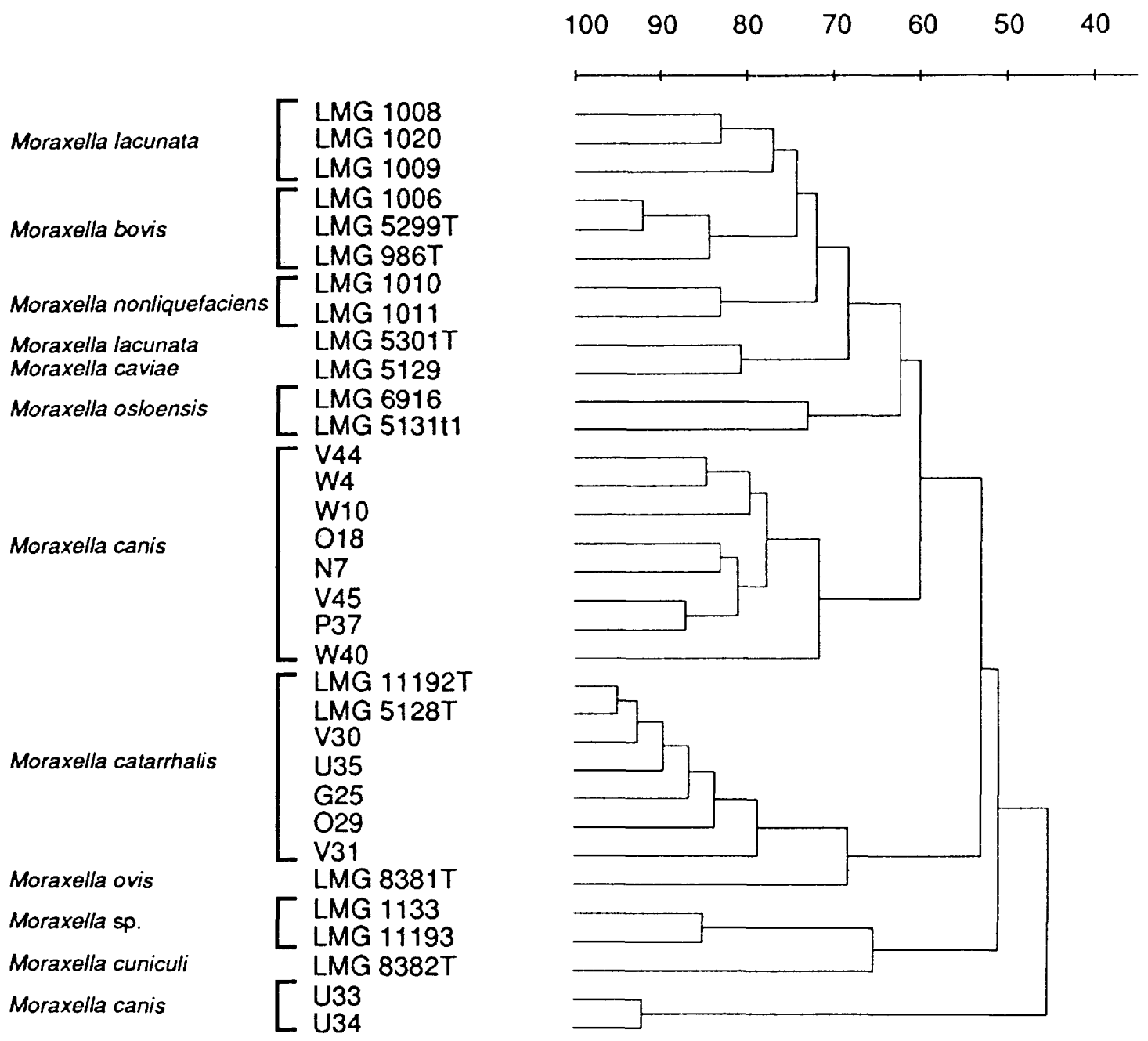

FIG. 2. Dendrogram based on average-linkage cluster analysis of SDS-PAGE protein patterns from representative strains of $M$. catarrhalis, M. canis, and other Moraxella species. The scale represents the Pearson product moment correlation coefficient converted to percentages.

4 shows the hybridization patterns of a number of representative strains. Among the eight genuine $M$. catarrhalis strains tested, only the rRNA gene restriction pattern of strain V31 differed slightly from the others and exhibited some resemblance to the strain NCTC 4103 (LMG 1133) pattern. Among the $15 \mathrm{M}$. canis isolates, seven different restriction fragment types could be recognized. However, the profiles had some common features which enabled us to distinguish the $M$. canis strains from $M$. catarrhalis strains and from other the bacterial species tested (data not shown). The doublet at the left of the $M$. canis restriction patterns is characteristic for $M$. canis strains. The only exception is strain N49. In strain N49 the upper band of the doublet is absent and two higher-molecular-weight bands are present (Fig. 4). None of the $M$. canis strains exhibited the lowmolecular-weight band at about $350 \mathrm{bp}$ (single band at the left) typically found in $M$. catarrhalis strains and strain NCTC 4103. The following eight strains belong to the restriction fragment length polymorphism type 1 group: V44, V45, N50, W10, N7 ${ }^{\mathrm{T}}$, U33, U34, and O18. Strains N51 and N53 belong to type 7, and strains N47 and N48 belong to type 5. Strains W40, W4, P37, and N49 stand apart and belong to the restriction fragment length polymorphism type $2,3,4$, and 6 groups, respectively (Fig. 4). From these results it is obvious that considerably more heterogeneity is found in $M$. canis than in $M$. catarrhalis. However, it is not uncommon that different banding patterns are observed in one species while some other species are extremely homogeneous $(1,12,32)$.

PCR analysis of the 16S rRNA gene and the 16S-23S rRNA spacer region. The use of PCR typing for taxonomic purposes is rather new and is still under development. However, this procedure might be preferred to classical restriction fragment length analyses, such as ribotyping, since there are fewer technical constraints and it is easier to perform while the informational value seems to be comparable. The results obtained after we separately amplified the $16 \mathrm{~S}-23 \mathrm{~S}$ rRNA spacer region and the $16 \mathrm{~S}$ rRNA gene are shown in Fig. 5 and 6, respectively.

Enzymatic amplification of the 16S-23S rRNA gene spacer region with primers 3 and 4 revealed a difference in fragment length between $M$. catarrhalis strains and $M$. canis strains. All eight $M$. catarrhalis strains examined yielded a fragment about 620 bp long, while the fragments of the $15 \mathrm{M}$. canis 


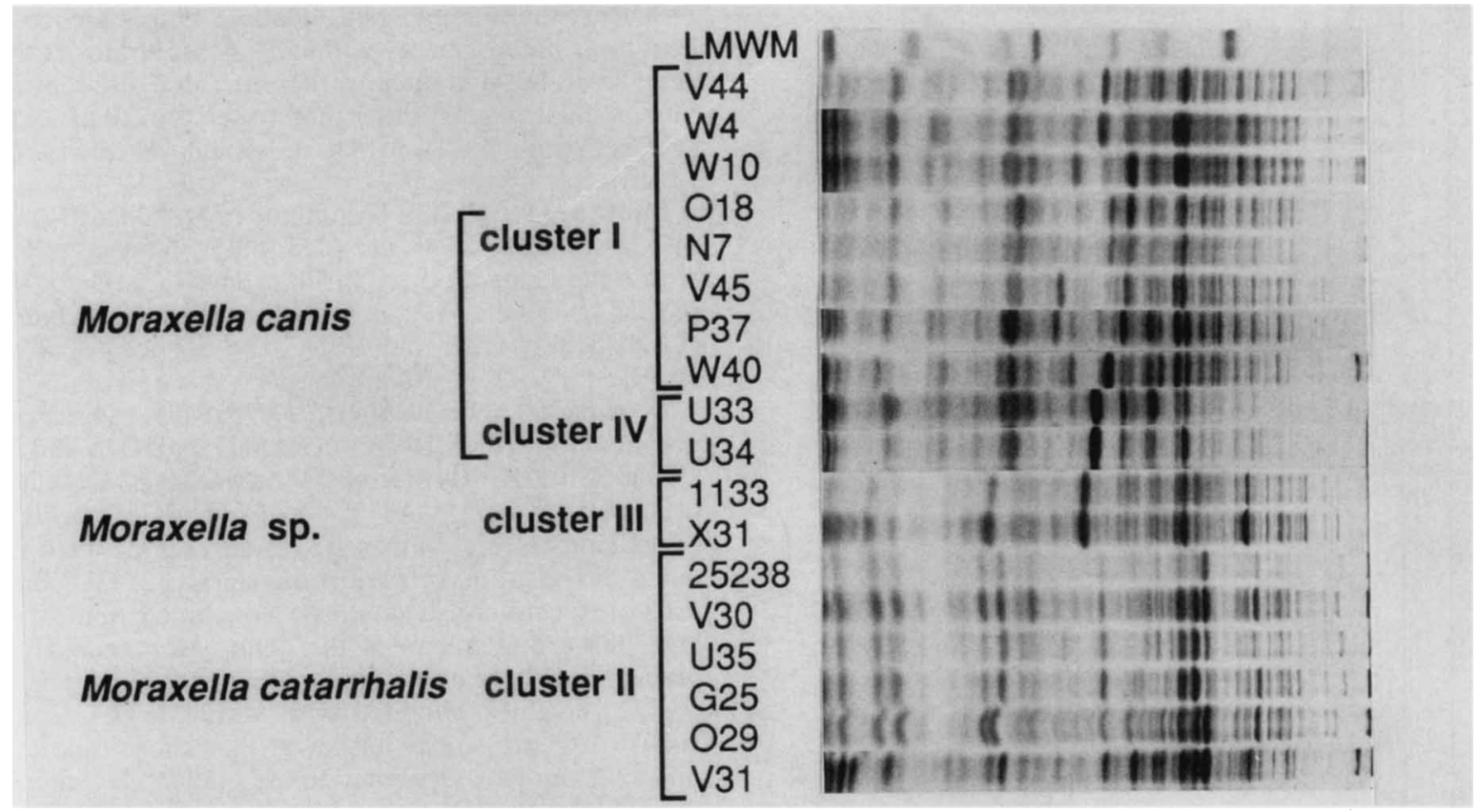

FIG. 3. Electropherograms of $M$. catarrhalis and $M$. canis strains and Moraxella sp. strain NCTC 4103 subclones LMG 1133 and X31. The low-molecular-weight markers (lane LMWM) were (from left to right) lysozyme (molecular weight, 14,500), trypsin inhibitor (20,100), trypsinogen $(24,000)$, carbonic anhydrase $(29,000)$, glyceraldehyde-3-phosphate dehydrogenase $(36,000)$, egg albumin $(45,000)$, and bovine albumin $(66,000)$.

strains and of strain NCTC 4103 were about 580 bp long. When DNA of $M$. nonliquefaciens ATCC $19975^{\mathrm{T}}$ was used as the target, a 670 -bp fragment was observed. $M$. osloensis ATCC 19961 yielded a fragment about 750 bp long. In addition, $M$. canis strains differed from $M$. catarrhalis, $M$. nonliquefaciens, and $M$. osloensis strains with respect to the presence of restriction sites for EcoRI and NcoI. A restriction site for EcoRI was observed in $M$. catarrhalis V31, but the spacer region fragments of other $M$. catarrhalis strains contained a restriction site for neither EcoRI nor NcoI. $M$. nonliquefaciens ATCC $19975^{\mathrm{T}}$ also did not possess recognition sites for EcoRI or NcoI, while in M. osloensis ATCC 19961, a restriction site for Eco RI was observed. In contrast, the spacer region fragments of strain NCTC 4103 and $M$. canis $\mathrm{W} 40, \mathrm{~N} 51$, and N53 possessed restriction sites for both enzymes and produced identical restriction patterns. The other $M$. canis strains lacked the $N c o$ I recognition site.

Evidently no length polymorphism could be observed on an agarose gel when the 16S rRNA genes were enzymatically amplified. When primers 1 and 2 were used, all of the strains examined produced a DNA fragment about $1,500 \mathrm{bp}$ long (data not shown). However, as illustrated in Fig. 6, after restriction endonuclease digestion with HindIII or EcoRI, DNA fragments originating from $M$. canis strains could readily be differentiated from DNA fragments originating from $M$. catarrhalis strains. When either HindIII or EcoRI was used, no differences in restriction patterns were observed among the $M$. catarrhalis strains studied. Strain NCTC 4103 could not be distinguished from genuine $M$. catarrhalis strains. Within $M$. canis, two types, both different from $M$. catarrhalis or $M$. nonliquefaciens, were observed when EcoRI was used. Strains N7 ${ }^{\mathrm{T}}, \mathrm{O} 18, \mathrm{~V} 45, \mathrm{~N} 47$, $\mathrm{N} 48, \mathrm{~N} 49$, and $\mathrm{N} 50$ belong to one group, while strains U33, U34, P37, W40, V44, W4, W10, N51, and N53 belong to a second group (Fig. 6). M. osloensis could not be differenti- ated from the first group of $M$. canis strains when EcoRI was used. When HindIII was used, all $M$. canis strains exhibited the same pattern and possessed one recognition site approximately $30 \mathrm{bp}$ from the beginning of the amplicon, in contrast to $M$. osloensis, which did not possess any sites for HindIII. Because of the small fragment cleaved off, the difference between the two species was more apparent when EcoRIHindIII double digestion was used (data not shown).

By combining the results obtained with the HindIII and EcoRI digests of the 16S rRNA gene fragment and the EcoRI and $N c o$ I digests of the spacer region fragment, a total of seven restriction sites could be examined. Among the $M$. canis strains, we ended up with three different types. Type 1 included strains $\mathrm{N}^{\mathrm{T}}$, O18, V45, N47, N48, N49, and N50, each of which had two EcoRI sites and one HindIII site. Type 2 (three EcoRI sites and one HindIII site) included strains U33, U34, P37, V44, W4, and W10. The strains exhibiting a type 3 pattern (one HindIII site, three EcoRI sites, and one NcoI site) were W40, N51, and N53. Type 2 and 3 strains and type 1 and 2 strains differ in only one restriction site, while type 1 strains differ from type 3 strains in two sites.

All of the $M$. catarrhalis strains except V31 are the same type. At least three to five of the seven sites examined differ between typical $M$. catarrhalis strains and strains of $M$. canis. For strain NCTC 4103 , a total of two differences were observed compared with typical $M$. catarrhalis strains; with $M$. canis strains we found three to five differences. Two to four differences occurred between $M$. canis strains and $M$. osloensis ATCC 19961. It is also noteworthy that only one difference between $M$. catarrhalis strains and the type strain of $M$. nonliquefaciens was detected. However, the exact taxonomic consequences of these observations cannot be fully evaluated at this time since it is not known at which taxonomic level the observed differences are relevant. Nev- 


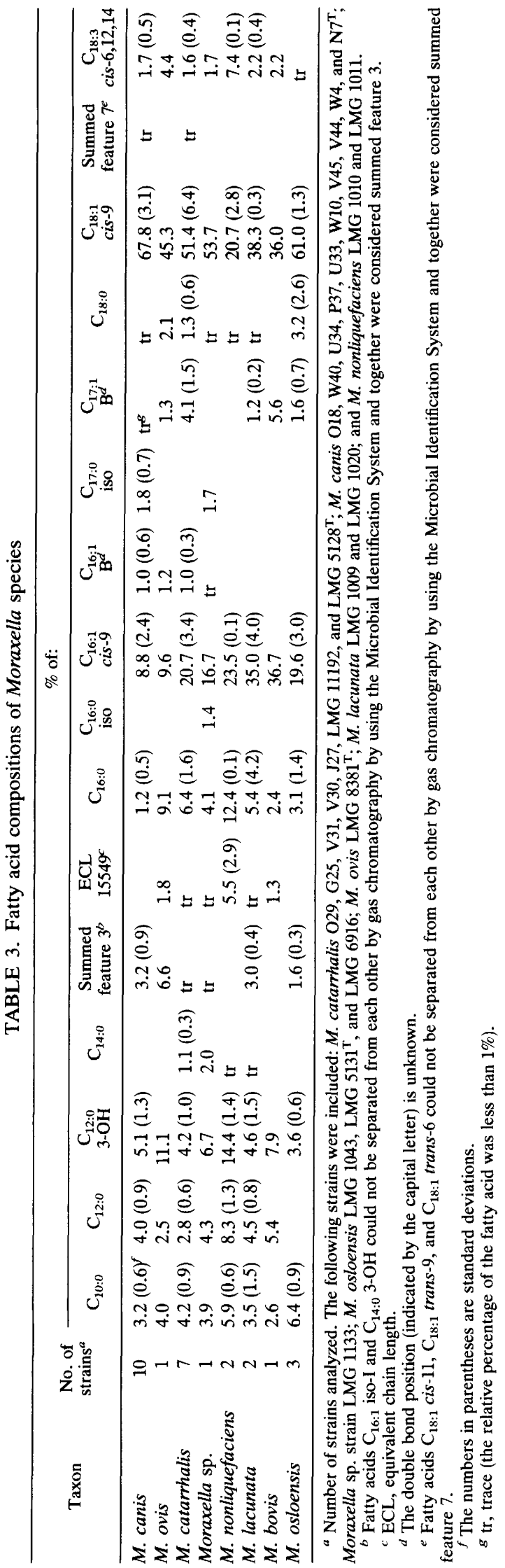

ertheless, the results again illustrate the existence of some genotypic heterogeneity within $M$. canis strains at the rRNA gene level, but it is obvious that the three different types are more similar to each other than to the typical $M$. catarrhalis strains, strain NCTC 4103, or strains of other Moraxella species.

Mol\% G+C. The $\mathrm{G}+\mathrm{C}$ contents of $M$. canis P37, U33, and $\mathrm{N}^{\mathrm{T}}$ were $45.9,47.4$, and $47.5 \mathrm{~mol} \%$, respectively. This is within the range reported for the genus Moraxella (40 to 47.5 mol\% [4]). The $\mathrm{G}+\mathrm{C}$ contents of three $M$. catarrhalis strains (LMG $5128^{\mathrm{T}}, \mathrm{G} 25$, and V31) were between 43.3 and 43.7 mol\%.

DNA-rRNA hybridizations. DNA-rRNA hybridization experiments in which DNAs from $M$. canis O18 and U33 and ${ }^{3} \mathrm{H}$-labeled 23S rRNA from $M$. lacunata ATCC 17952 were used yielded a $T_{m(e)}$ of $75.4^{\circ} \mathrm{C}$ for both $M$. canis strains. Since similar $T_{m(e)}$ values $\left(75.6\right.$ and $\left.75.7^{\circ} \mathrm{C}\right)$ were found by using DNAs from $M$. catarrhalis ATCC $25238^{\mathrm{T}}$ and NCTC 4103, respectively, it could be concluded that strains $\mathrm{O} 18$ and U33 are members of the genus Moraxella and consequently members of the family Moraxellaceae. The fact that the $T_{m(e)}$ values obtained with strains ATCC $25238^{\mathrm{T}}$ and NCTC 4103 are somewhat lower than those reported previously (28) may be attributed to the gradual decomposition of the ${ }^{3} \mathrm{H}$-labeled rRNA during storage. Previously published DNA-rRNA hybridization studies $(27,28)$ demonstrated that Moraxella species, including $M$. catarrhalis, are not related to unequivocal members of the emended family Neisseriaceae. For Moraxella species $T_{m(e)}$ values as low as 60 to $65^{\circ} \mathrm{C}$ were found with Neisseria flavescens rRNA (27). The available data also proved that the type strain of $N$. canis undoubtedly belongs to the Neisseriaceae ( $T_{m(e)}$ versus $N$. flavescens rRNA, $76.3^{\circ} \mathrm{C}$ ). In combination with our results, it can be concluded that $M$. canis and $N$. canis are clearly separate bacterial species.

DNA-DNA hybridizations. The degrees of binding obtained by using the initial renaturation rate DNA-DNA hybridization method with DNAs from $M$. canis P37, U33, and N7 $7^{\mathrm{T}}$ ranged from 82 to $91 \%$. Between these strains and strain NCTC 4103 the degrees of binding were between 52 and $61 \%$. Low to moderate DNA homology values (degrees of binding between 9 and 38\%) were found between the $M$. canis strains and $M$. catarrhalis ATCC $25238^{\mathrm{T}}, \mathrm{G} 25$, and V31, as well as M. osloensis ATCC 19961. Data obtained under stringent conditions for hybridization between dotspotted DNAs of a variety of strains and ${ }^{32} \mathrm{P}$-labeled DNA of M. canis $\mathrm{O} 18$ confirmed that strains O18, N7, U33, and U34 are more closely related to each other than to $M$. catarrhalis strains, strain NCTC 4103 , and one strain each of $M$. ovis, $M$. caviae, $M$. cuniculi, $M$. lacunata, $M$. nonliquefaciens, M. osloensis, Psychrobacter immobilis, Acinetobacter calcoaceticus, and Neisseria gonorrhoeae (data not shown). These results indicate that $M$. canis strains are not particularly closely related to $M$. catarrhalis or other Moraxella species and thus belong to a separate species.

Taxonomic implications. Biochemical as well as genotypic heterogeneity among $M$. canis strains was observed by using several techniques. The phenotypic heterogeneity was particularly obvious when the SDS-PAGE profiles of the cellular proteins were compared. However, this technique attempts to detect differences at a rather fine taxonomic level. Ribotyping and PCR analysis of the 16S rRNA gene and the 16S-23S rRNA spacer region also revealed heterogeneity. In fact, DNA-DNA hybridization results showed that strains belonging to different ribotype groups or strains having different PCR types may still be related above the species 


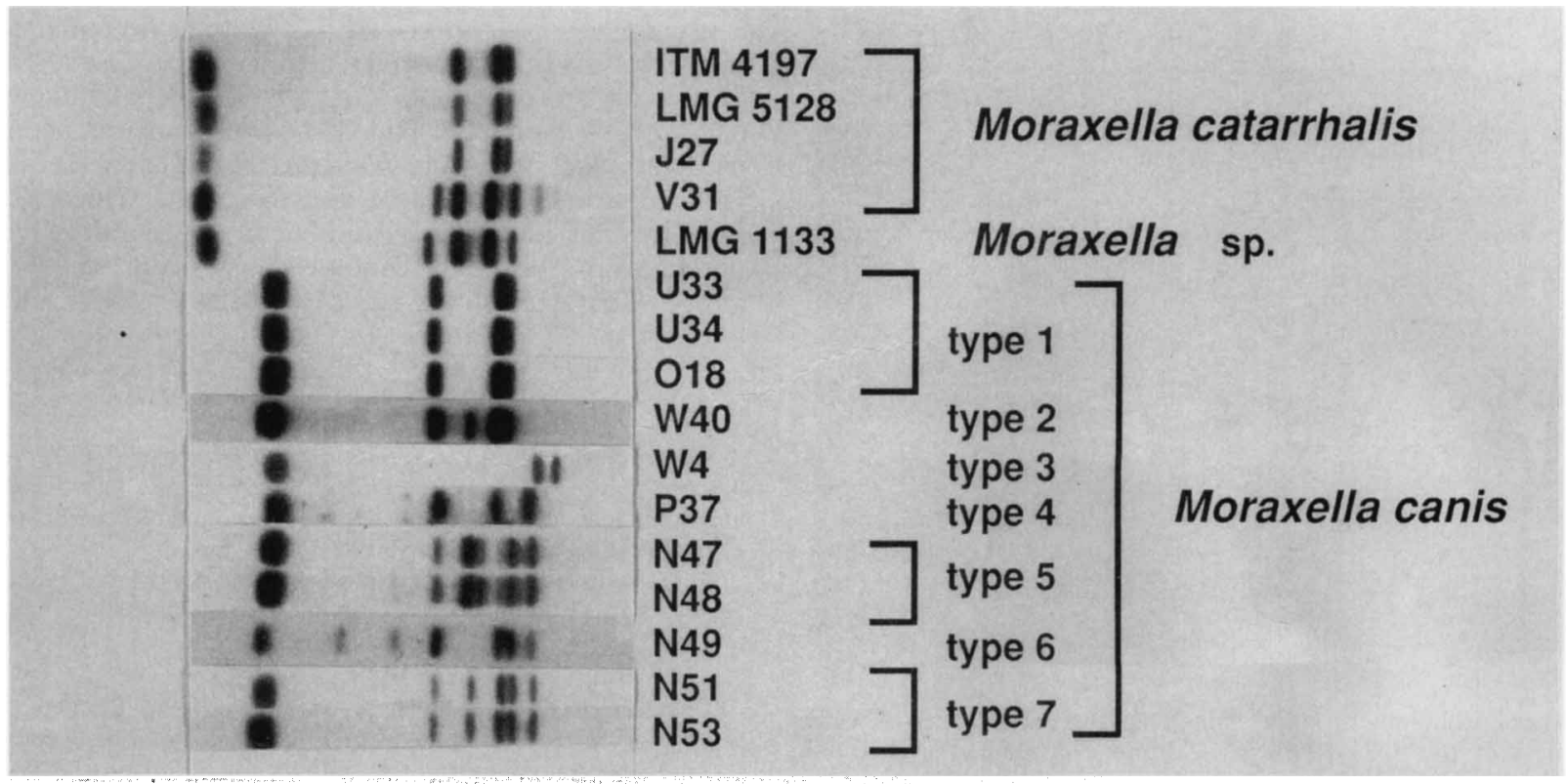

FIG. 4. Southern hybridization of HindIII-digested genomic DNAs from representative strains of $M$. catarrhalis and $M$. canis and from Moraxella sp. strain NCTC 4103 with a mixture of oligonucleotide probes 1, 5, and 6.

level (e.g., strains $\mathrm{N}^{\mathrm{T}}$ and $\mathrm{P} 37$, which exhibit a degree of binding of $90 \%$ ). Alternatively, these techniques also revealed some common properties among the $M$. canis strains examined which were not found in the other taxa studied. The fact that $M$. canis strains constitute a single cluster is further corroborated by the fatty acid analysis results. Strains U33 and U34 are undoubtedly phenotypically and serologically the most aberrant strains. However, these strains are indistinguishable from certain other $M$. canis strains by PCR analysis and ribotyping. Moreover, strain U33 exhibits degrees of binding between 82 and $91 \%$ with strains $\mathrm{N} 7^{\mathrm{T}}$ and P37. Thus, U33 and $\mathrm{U} 34$ are genuine $M$. canis strains.

The combined data indicate that $M$. canis strains are not related to $M$. catarrhalis above the species level, despite the fact that $M$. canis strains phenotypically resemble $M$. catarrhalis strains (DNase-producing, gram-negative, asaccharolytic cocci) and show some serological cross-reactivity. However, serology should not be considered a highly reliable taxonomic technique. The available data also exclude the possibility of a relationship with other Moraxella species. From these results it can be concluded that the $M$. canis strains are a separate phenotypic and genotypic entity, different from any species described previously. Consequently, the creation of a new species for this group of organisms can be justified. As these strains can be assigned to the genus Moraxella on the basis of DNA-rRNA hybridization results (which also exclude the possibility of a relationship with $N$. canis or other Neisseria species), and since most of the isolates originate from dogs, the name $M$. canis is proposed. Also, the phenotypic and chemotaxonomic characteristics of these strains are consistent with the descriptions of the genus Moraxella (5) and the family Moraxellaceae (28)

Position of strain NCTC 4103. Catlin and Cunningham (7), Bøvre (4), and Baumann et al. (3) provided genotypic and phenotypic evidence that strain NCTC 4103 is related to $M$. catarrhalis but cannot be considered a genuine $M$. catarrhalis strain. Our data cannot unequivocally elucidate the exact taxonomic position of this strain. The fatty acid profiles and DNA restriction patterns of strain NCTC 4103 resemble those of $M$. catarrhalis strains but are not entirely identical. No DNA-DNA homology was found between $M$. catarrhalis strains and strain NCTC 4103. However, these results are in conflict with previously reported DNA-DNA hybridization results showing a significant level of DNA

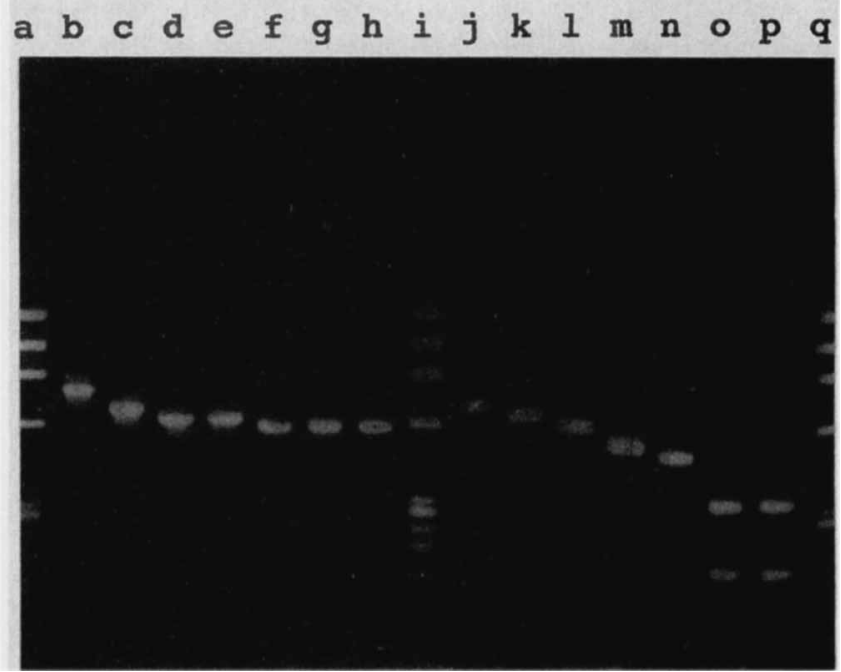

FIG. 5. Ethidium bromide-stained agarose $(1.8 \%)$ gel of PCR products of the 16S-23S rRNA gene spacer region. Lanes $b$ through $h$ contained undigested material; lanes $j$ through $p$ contained material digested with $E c o$ RI and $N c o I$. The following strains were used: $M$. osloensis ATCC 19961 (lanes b and j), $M$. nonliquefaciens ATCC $19975^{\mathrm{T}}$ (lanes c and k), $M$. catarrhalis LMG $5128^{\mathrm{T}}$ (lanes d and $\mathrm{l}$ ), $M$. catarrhalis $\mathrm{V} 31$ (lanes e and $\mathrm{m}$ ), $M$. canis $\mathrm{N}^{\mathrm{T}}$ (lanes $\mathrm{f}$ and $\mathrm{n}$ ), $M$. canis W40 (lanes $\mathrm{g}$ and $\mathrm{o}$ ), and Moraxella sp. strain NCTC 4103 (lanes $h$ and $p$ ). Lanes $a, i$, and $q$ contained the molecular weight marker ( $\phi$ X 174 DNA digested with HaeIII). 


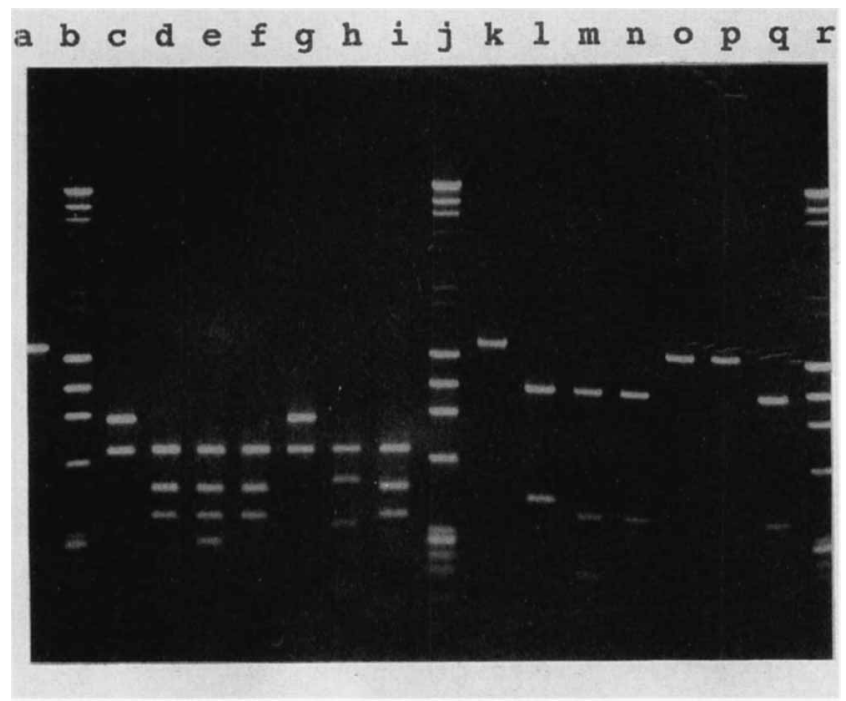

FIG. 6. Ethidium bromide-stained agarose (1.6\%) gel of PCR products of the 16S rRNA gene. Lane a contained undigested material from $M$. osloensis ATCC 19961; lanes c through i contained amplicons digested with EcoRI; and lanes k through q contained amplicons digested with HindIII. The following strains were used: M. osloensis ATCC 19961 (lanes $\mathrm{c}$ and k), $M$. nonliquefaciens ATCC $19975^{\mathrm{T}}$ (lanes d and l), $M$. catarrhalis LMG $5128^{\mathrm{T}}$ (lanes e and $\mathrm{m}$ ), $M$. catarrhalis V31 (lanes $\mathrm{f}$ and $\mathrm{n}$ ), $M$. canis $\mathrm{N} 7^{\mathrm{T}}$ (lanes $\mathrm{g}$ and $\mathrm{o}$ ), $M$. canis W40 (lanes $\mathrm{h}$ and $\mathrm{p}$ ), and Moraxella sp. strain NCTC 4103 (lanes $i$ and $q$ ). Lanes $b, j$, and $r$ contained the molecular weight marker ( $\lambda$ DNA digested with HindIII mixed with $\phi X 174$ DNA digested with HaeIII). Agarose gel electrophoresis of all of the undigested amplicons (data not shown) proved that the smallest fragment (ca. $280 \mathrm{bp}$ ) in lane e is not a result of digestion of the $16 \mathrm{~S}$ rRNA gene of $M$. catarrhalis LMG $5128^{\mathrm{T}}$ but is an aspecific PCR product that itself is cut by HindIII (lane $\mathrm{m}$ ).

homology (59\%) (28). Moreover, in this study we found significant levels of DNA homology (52 to 61\%) between strain NCTC 4103 and $M$. canis strains, which suggests that strain NCTC 4103 might be a member of this species. However, in many other aspects (fatty acid profile and restriction and protein patterns) strain NCTC 4103 differs from $M$. canis strains. In conclusion, strain NCTC 4103 seems to be situated somewhere between $M$. catarrhalis and $M$. canis. In our opinion the assignment of Moraxella sp. strain NCTC 4103 to a species should be postponed until more unambiguous data are available.

Description of Moraxella canis sp. nov. Moraxella canis (ca'nis. L. gen. n. canis, of a dog). Cells are cocci (diameter, about 0.8 to $1.3 \mu \mathrm{m}$ ) and usually occur in pairs or short chains. Gram-negative, but there may be a tendency to resist decolorization. A brown pigment may be observed on Mueller-Hinton agar. Cells are nonmotile in liquid medium. Chemoorganotrophic and aerobic. Mesophilic. Cell growth is usually observed on medium containing mineral salts and ammonium acetate, lactose bromothymol blue agar, eosinemethylene blue agar, Mueller-Hinton agar, and MacConkey agar at $37^{\circ} \mathrm{C}$. Growth occurs on Mueller-Hinton agar at room temperature. No growth occurs in the presence of $6 \% \mathrm{NaCl}$ or at $5^{\circ} \mathrm{C}$. Usually indifferent to bile salts. Oxidase, catalase, extracellular DNase, butyrate esterase, and $\gamma$-glutamylaminopeptidase are produced. Phenylalanine deaminase, indole, urease, and carbonic anhydrase are not produced. No acid is produced from glucose. Tween 80 and starch are not hydrolyzed. Autoagglutination in physiological solution is usually not observed. Gelatin and serum are not liquefied. No hemolysis of human and sheep blood occurs. The major fatty acids are oleic acid $\left(\mathrm{C}_{18: 1}\right.$ cis-9) and palmitoleic acid $\left(C_{16: 1}\right.$ cis-9). Isoheptadecanoic acid $\left(C_{17: 0}\right.$ iso $)$ is present in moderate amounts, and myristic acid $\left(C_{14: 0}\right)$ is absent. Isolated from the saliva of dogs or cats and occasionally from humans (dog bite wounds or blood). Pathogenicity is not known. The $\mathrm{G}+\mathrm{C}$ content ranges from 45.9 to 47.5 mol\%. The type strain is LMG $11194(=\mathrm{N} 7=$ CCUG $8415 \mathrm{~A})$.

\section{ACKNOWLEDGMENTS}

We are very grateful to Reinhilde Zelck for excellent secretarial assistance, to Dirk Dewettinck for the photographs, to Noëlla Paepe and Ann De Rouck for technical assistance, and to Fred Shapiro for critical reading of the manuscript.

M.G. is indebted to the National Fund for Medical Scientific Research of Belgium for research and personnel grants.

\section{REFERENCES}

1. Andersen, J. K., and N. A. Saunders. 1990. Epidemiological typing of Yersinia enterocolitica by analysis of restriction fragment length polymorphisms with a cloned ribosomal RNA gene. J. Med. Microbiol. 32:179-187.

2. Bailie, W. E., E. C. Stowe, and A. M. Schmitt. 1978. Aerobic bacterial flora of oral and nasal fluids of canines with reference to bacteria associated with bites. J. Clin. Microbiol. 7:223-231.

3. Baumann, P., M. Doudoroff, and R. Y. Stanier. 1968. Study of the Moraxella group. I. Genus Moraxella and the Neisseria catarrhalis group. J. Bacteriol. 95:58-73.

4. Bøvre, K. 1967. Transformation and DNA base composition in taxonomy with special reference to recent studies in Moraxella and Neisseria. Acta Pathol. Microbiol. Scand. 69:123-144.

5. Bøvre, K. 1984. Family VIII. Neisseriaceae Prévot 1933, $119^{\mathrm{AL}}$, p. 288-309. In N. R. Krieg and J. G. Holt (ed.), Bergey's manual of systematic bacteriology, vol. 1. The Williams \& Wilkins Co., Baltimore.

6. Catlin, B. W. 1991. Branhamaceae fam. nov., a proposed family to accommodate the genera Branhamella and Moraxella. Int. J. Syst. Bacteriol. 41:320-323.

7. Catlin, B. W., and L. S. Cunningham. 1964. Genetic transformation of Neisseria catarrhalis by deoxyribonucleate preparations having different average base compositions. J. Gen. Microbiol. 37:341-352.

8. De Ley, J. 1970. Reexamination of the association between melting point, buoyant density, and chemical base composition of deoxyribonucleic acid. J. Bacteriol. 101:738-754.

9. De Ley, J., H. Cattoir, and A. Reynaerts. 1970. The quantitative measurement of DNA hybridization from renaturation rates. Eur. J. Biochem. 12:133-142.

10. De Ley, J., and J. De Smedt. 1975. Improvements of the membrane filter method for DNA:rRNA hybridization. Antonie van Leeuwenhoek J. Microbiol. Serol. 41:287-308.

11. De Ley, J., and J. Van Muylem. 1963. Some applications of deoxyribonucleic acid base composition in bacterial taxonomy. Antonie van Leeuwenhoek J. Microbiol. Serol. 29:344-358.

12. Grimont, F., and P. A. D. Grimont. 1986. Ribosomal ribonucleic acid gene restriction patterns as potential taxonomic tools. Ann. Inst. Pasteur/Microbiol. (Paris) 137B:165-175.

13. Hoke, C., and N. A. Vedros. 1982. Taxonomy of the neisseriae: fatty acid analysis, aminopeptidase activity, and pigment extraction. Int. J. Syst. Bacteriol. 32:51-56.

14. Hollis, D. G., M. I. Daneshvar, L. Meadows, J. Jordan, and C. W. Moss. 1991. Characterization of CDC group NO-1, a fastidious nonoxidative gram-negative organism associated with dog and cat bites, abstr. D-233, p. 117. Abstr. 91st Gen. Meet. Am. Soc. Microbiol. 1991.

15. Jantzen, E., K. Bryn, T. Bergan, and K. Bøvre. 1974. Gas chromatography of bacterial whole cell methanolysates. V. Fatty acid composition of neisseriae and moraxellae. Acta Pathol. Microbiol. Scand. Sect. B 82:767-779. 
16. Jantzen, E., O. M. Kvalheim, T. A. Hauge, N. Hagen, and K. Bøvre. 1987. Grouping of bacteria by Simca pattern recognition on gas chromatographic lipid data: patterns among Moraxella and rod-shaped Neisseria. Syst. Appl. Microbiol. 9:142-150.

17. Kamme, C., M. Vang, and S. Stahl. 1983. Transfer of betalactamase production in Branhamella catarrhalis. Scand. J. Infect. Dis. 15:225-226.

18. Laemmli, U. K. 1970. Cleavage of structural proteins during the assembly of the head of bacteriophage T4. Nature (London) 227:680-685.

19. Lambert, M. A., D. G. Hollis, C. W. Moss, R. E. Weaver, and M. L. Thomas. 1971. Cellular fatty acids of nonpathogenic Neisseria. Can. J. Microbiol. 17:1491-1502.

20. Maniatis, T., E. F. Fritsch, and J. Sambrook. 1982. Molecular cloning: a laboratory manual. Cold Spring Harbor Laboratory, Cold Spring Harbor, N.Y.

21. Marmur, J., and P. Doty. 1962. Determination of the base composition of deoxyribonucleic acid from its thermal denaturation temperature. J. Mol. Biol. 5:109-118.

22. Marmur, J. A. 1961. A procedure for the isolation of deoxyribonucleic acid from micro-organisms. J. Mol. Biol. 3:208-218.

23. McFaddin, J. F. 1980. Biochemical tests for identification of medical bacteria, 2nd ed. Williams \& Wilkins Co., Baltimore.

24. Reed, K. C., and D. A. Mann. 1985. Rapid transfer of DNA from agarose gels to nylon membranes. Nucleic Acids Res. 13:72077221.

25. Riou, J. Y., J. Buissière, C. Richard, and M. Guibourdenche. 1982. Intérêt de la recherche de la gamma-glutamyl-transférase chez les Neisseriaceae. Ann. Microbiol. (Inst. Pasteur) 133A: 387-392.

26. Riou, J. Y., and M. Guibourdenche. 1986. Branhamella catarrhalis. New methods of bacterial diagnosis. Drugs 31(Suppl. 3):1-6.

27. Rossau, R., G. Vandenbussche, S. Thielemans, P. Segers, H. Grosch, E. Göthe, W. Mannheim, and J. De Ley. 1989. Ribosomal ribonucleic acid cistron similarities and deoxyribonucleic acid homologies of Neisseria, Kingella, Eikenella, Simonsiella, Alysiella, and Centers for Disease Control groups EF-4 and M-5 in the emended family Neisseriaceae. Int. J. Syst. Bacteriol. 39:185-198.

28. Rossau, R., A. Van Landschoot, M. Gillis, and J. De Ley. 1991. Taxonomy of Moraxellaceae fam. nov., a new bacterial family to accomodate the genera Moraxella, Acinetobacter, and Psychrobacter and related organisms. Int. J. Syst. Bacteriol. 41:310-319.

29. Rossau, R., E. Vanmechelen, J. De Ley, and H. Van Heuver- swyn. 1989. Specific Neisseria gonorrhoeae DNA probes derived from ribosomal RNA. J. Gen. Microbiol. 135:1735-1745.

30. Saphir, D. A., and G. R. Carter. 1976. Gingival flora of the dog with special reference to bacteria associated with bites. J. Clin. Microbiol. 3:344-349.

31. Sneath, P. H. A., and R. R. Sokal. 1973. Numerical taxonomy. The principles and practice of numerical classification. W. $\mathrm{H}$. Freeman and Co., San Francisco.

32. Stull, T. L., J. J. LiPuma, and T. D. Edind. 1988. A broadspectrum probe for molecular epidemiology of bacteria: ribosomal RNA. J. Infect. Dis. 157:280-286.

33. Sugimoto, C., E. Miyagawa, M. Nakazawa, K. Mitani, and Y. Isayama. 1983. Cellular fatty acid composition comparisons of Haemophilus equigenitalis and Moraxella species. Int. J. Syst. Bacteriol. 33:181-187.

34. Vandamme, P., E. Falsen, B. Pot, B. Hoste, K. Kersters, and J. De Ley. 1989. Identification of EF group 22 campylobacters from gastroenteritis cases as Campylobacter cancisus. J. Clin. Microbiol. 27:1775-1781.

35. Vaneechoutte, M., G. Verschraegen, G. Claeys, and P. Flamen. 1988. Rapid identification of Branhamella catarrhalis with 4-methylumbelliferyl butyrate. J. Clin. Microbiol. 26:1227-1228.

36. Vaneechoutte, M., G. Verschraegen, G. Claeys, and A. M. Van Den Abeele. 1988. Selective medium for Branhamella catarrhalis with acetazolamide as a specific inhibitor of Neisseria spp. $\mathrm{J}$. Clin. Microbiol. 26:2544-2549.

37. Vaneechoutte, M., G. Verschraegen, G. Claeys, and A. M. Van Den Abeele. 1990. Serological typing of Branhamella catarrhalis strains on the basis of lipopolysaccharide antigens. J. Clin. Microbiol. 28:182-187.

38. Vauterin, L., P. Yang, B. Hoste, M. Vancanneyt, E. L. Civerolo, J. Swings, and K. Kersters. 1991. Differentiation of Xanthomonas campestris pv. citri strains by sodium dodecyl sulfatepolyacrylamide gel electrophoresis of proteins, fatty acid analysis, and DNA-DNA hybridization. Int. J. Syst. Bacteriol. 41:535-542.

39. Voller, A., C. C. Draper, D. E. Bidwell, and A. Bartlett. 1972. Microplate enzyme-linked immunosorbent assay for Chagas' diseaese. Methods Carbohydr. Chem. 5:83-91.

40. Wüst, J., G. V. Doern, and A. von Graevenitz. 1988. Branhamella catarrhalis: fatty acid and lipopolysaccharide analysis of an atypical strain from blood culture. Diagn. Microbiol. Infect. Dis. 10:131-134. 